\title{
Estrutura e Conservação de um Trecho de Floresta Estacional em Piraí, RJ
}

\author{
Alexandre dos Santos Medeiros ${ }^{1}$, Marcos Gervasio Pereira ${ }^{1}$, Denise Monte Braz ${ }^{2}$ \\ ${ }^{1}$ Departamento de Solos, Universidade Federal Rural do Rio de Janeiro - UFRRJ, Seropédica/RJ, Brasil \\ ${ }^{2}$ Departamento de Botânica, Universidade Federal Rural do Rio Janeiro - UFRRJ, Seropédica/RJ, Brasil
}

\section{RESUMO}

O objetivo deste estudo foi a caracterização florística e estrutural de um fragmento de floresta estacional em Piraí, RJ, visando a determinação de seu estágio sucessional. O Parque Municipal da

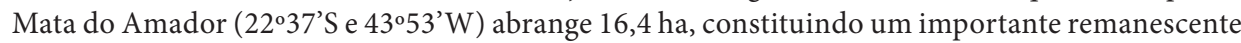
florestal urbano. Foram instaladas 15 parcelas de $10 \times 10$ metros, sendo o diâmetro de inclusão dos indivíduos maior ou igual a 5 centímetros. Foram mensurados 176 indivíduos, reunidos em 24 famílias, 46 gêneros e 51 espécies. A família com maior riqueza foi Fabaceae, os gêneros mais abundantes foram Cupania L., Casearia Jacq e Eugenia L. e a espécie com maior valor de importância foi Sorocea bonplandii. Ficou demonstrado que a Mata do Amador apresenta diversidade considerável de espécies $\left(\mathrm{H}^{\prime}=3,517\right.$ natsind $\left.^{-1}\right)$ e equabiliadade elevada $\left(J^{\prime}=0,884\right)$, sendo classificada como fragmento de floresta secundária em estágio médio de regeneração.

Palavras-chave: Floresta Atlântica, Médio Vale do Paraíba do Sul, fitossociologia, florística, sudeste brasileiro.

\section{Structure and Conservation of a Stretch of Seasonal Forest in Pirai-RJ}

\begin{abstract}
This study aimed the floristic and structural characterization of a stretch of seasonal forest in the Municipality of Pirai, State of Rio de Janeiro, in order to determine its successional stage. The Parque Municipal da Mata do Amador has an area of 16.4 ha (22.37'S and 43.53'W), where 15 plots of $10 \times 10$ meters were installed. Plants with DAP $\geq 5 \mathrm{~cm}$ were measured, which totalized 176 specimens, encompassing 24 families, 46 genera and 51 species. The richest family was Fabaceae. The most abundant genera were Cupania L., Casearia Jacq and Eugenia L. The species with the highest importance value was Sorocea bonplandii. It was demonstrated tha the Mata do Amador has considerable species diversity $\left(\mathrm{H}^{\prime}{ }^{\prime}=3.517\right.$ natsind $\left.{ }^{-1}\right)$ and high equability $\left(\mathrm{J}^{\prime}=0.884\right)$, classified as a secondary forest stretch in a intermediate stage of regeneration.
\end{abstract}

Keywords: Atlantic Forest, Eastern Vale do Paraíba do Sul, phytosociological, floristic, southeastern Brazil. 


\section{INTRODUÇÃO}

No Médio Vale do Paraíba do Sul, a antropização das formações florestais da Floresta Atlântica pode ser considerada tardia, tendo em vista que até meados do século XIX o sul do estado do Rio de Janeiro era apenas rota de passagem para Minas Gerais e São Paulo (Dean, 1996). Até então predominou na região a agricultura de subsistência, restrita principalmente às baixadas, enquanto as encostas se mantiveram preservadas. A fertilidade natural dos solos florestais na região e a localização estratégica para o escoamento da produção, entretanto, logo impulsionaram na região a conversão de florestas em lavouras de café, dando início ao mais importante ciclo de produção do Brasil até aquele momento (Dean, 1996).

A declividade acentuada, a retirada da cobertura florestal das encostas e o uso intensivo dos recursos edáficos favoreceram a rápida degradação dos solos na região do Médio Vale do Paraíba do Sul, promovendo o declínio acentuado da produção de café em poucas décadas. Com o colapso do sistema produtivo, as áreas de lavoura foram gradativamente substituídas por pastagens, condição que agravou os processos erosivos e impediu a resiliência das comunidades florestais na região. Como consequência, observa-se atualmente o assoreamento do sistema hídrico superficial, a remoção dos horizontes superficiais do solo e a diminuição de sua capacidade produtiva. Com relação à biota, a fragmentação de hábitat e supressão de extensas áreas de floresta causou perdas irreparáveis e, possivelmente, a extinção de dezenas de espécies vegetais, em geral pouco conhecidas quanto à classificação e potencialidades (Câmara, 1991; Oliveira et al., 1995).

Adicionada a grande devastação sofrida pela vegetação local, restrita na atualidade a pequenos fragmentos florestais isolados, as estratégias para conservação da biodiversidade no estado do Rio de Janeiro (Bergalho, 2009) apontam a falta de conhecimento, especialmente em boa parte da Região do Médio Paraíba, ao sul do estado. Essas regiões ainda abrigam florestas remanescentes e esforços para o preenchimento dessas lacunas são essenciais para o conhecimento da flora do estado e da Floresta Atlântica como um todo.

O município de Piraí está inserido na região do Médio Vale do Paraíba do Sul e em sua porção central encontra-se o Parque Municipal da Mata do Amador, às margens do Rio Piraí. Criado em 8 de abril de 1997, pretendia preservar o principal remanescente de Floresta Atlântica próximo ao centro da cidade, permitir a conservação da diversidade local, a manutenção de suas funções ecológicas, a oferta de espaço para a educação ambiental e para a apreciação da natureza aos moradores da cidade.

Para o delineamento de ações efetivas que possibilitem a recuperação e conservação de ecossistemas regionais é necessário conhecimento das comunidades vegetais e da dinâmica das paisagens. Logo, se faz necessária a realização de estudos florísticos e fitossociológicos para o entendimento da estrutura e composição florística dessas comunidades (Oliveira, 1998; Vuono, 2002; Vilela et al., 1994). Este estudo teve como objetivo a caracterização florística e estrutural, a determinação da diversidade local e a classificação do estágio sucessional do fragmento florestal que constitui o Parque Municipal da Mata do Amador. Pretende fornecer informações importantes para a confecção e implementação do plano de manejo da referida unidade de conservação e promover o conhecimento da flora remanescente dessa região do sul do estado.

\section{MATERIAL E MÉTODOS}

O município de Piraí está localizado no sul do estado do Rio de Janeiro, entre as coordenadas $22^{\circ} 43^{\prime} \mathrm{Se}$

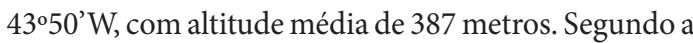
classificação Köppen (1948), o clima da região pode ser classificado como Cwa - clima temperado de inverno seco e verão chuvoso e Am - clima tropical chuvoso com inverno seco (Oliveira, 1998), apresentando temperatura média máxima de $29,1^{\circ} \mathrm{C}$ em fevereiro e média mínima de $20,1^{\circ} \mathrm{C}$ em julho, com pluviosidade média anual de $1.238,5 \mathrm{~mm}$, chuvas abundantes em fevereiro e escassas em julho. O relevo regional é classificado como declivoso, sendo predominantes colinas, morrotes e morros baixos com pedoformas convexas, côncavas e lineares, de gradiente suave a médio, topos arredondados e subnivelados (Silva, 2008), constituindo uma paisagem típica do domínio morfoclimático Mares-de-Morros (Ab’Sáber, 1966).

O Parque Municipal da Mata do Amador abrange uma área de 16,4 ha, com altitude variando de 380 a 450 metros, declividade entre $25^{\circ}$ e $40^{\circ}$ e relevo classificado como fortemente ondulado (Santos et al., 
2005). A comunidade vegetal é classificada como Floresta Estacional Semidecidual Submontana, uma vez que apresenta estação seca acentuada, variando entre 4 a 6 meses, caducifólia de $20 \%$ a 50\% dos indivíduos arbóreos do conjunto florestal e por se encontrar entre as latitudes $16^{\circ}$ e $24^{\circ}$, com altitude média entre as cotas 50 a 500 metros (IBGE, 2012; Oliveira-Filho \& Fontes, 2000).

Considerando que a comunidade em estudo possui tamanho reduzido, o levantamento florístico e fitossociológico contou com o número máximo possível de 15 unidades amostrais de $10 \times 10$ metros ao longo da trilha principal do parque, totalizando 0,15 ha de amostragem. A alocação das unidades obedeceu às distâncias mínimas de 30 metros entre parcelas e 15 metros até a trilha principal, a fim de reduzir o efeito de borda. Foram amostrados todos os indivíduos com DAP $\geq 5 \mathrm{~cm}$. A altura total foi estimada com base em vara de podão ( $2 \mathrm{~m})$. O material botânico foi coletado preferencialmente com flores e/ou frutos, anotando-se as características morfológicas vegetativas e reprodutivas. Todo material coletado foi herborizado segundo as técnicas usuais em Botânica (IBGE, 2012) e depositado no Herbário do Departamento de Botânica (RBR) da UFRRJ (Universidade Federal Rural do Rio de Janeiro). As determinações taxonômicas foram realizadas com auxílio de bibliografia especializada, comparação com o acervo do herbário RBR ou por meio de consulta a especialistas. O sistema de classificação segue APG III (Souza \& Lorenzi, 2012) e a nomenclatura foi atualizada através da Lista de Espécies da Flora do Brasil (JBRJ, 2014). As informações referentes ao grupo ecológico e forma de dispersão das sementes foram obtidas com o auxílio da bibliografia especializada (Lorenzi, 2009; Carvalho, 2003; Lima \& Guedes-Bruni, 1996; Morim, 2006; Menezes \&Araújo, 2005) e da Flora do Brasil (JBRJ, 2014), além de observações de campo.

A estrutura horizontal e os parâmetros fitossociológicos (média das alturas e diâmetros, área basal, densidade absoluta, densidade relativa, frequência absoluta, frequência relativa, dominância absoluta, dominância relativa, valor de cobertura e valor de importância) foram calculados segundo Felfili et al. (2011), utilizando-se o software MS Excel. A suficiência amostral foi verificada através do método proposto por Cain (1938) apud Schilling \& Batista (2008), que considera amostragem adequada aquela em que, a um aumento de $10 \%$ da área amostrada, o número de espécies novas não se revela superior a $10 \%$ do total de espécies encontradas.

O enquadramento do estágio sucessional da área de estudo seguiu o critério estabelecido pela resolução Conama n. 6, de 4 de maio de 1994, que estabelece definições e parâmetros mensuráveis para análise de sucessão ecológica na Floresta Atlântica no Estado do Rio de Janeiro (Brasil, 2008).

\section{RESULTADOS E DISCUSSÃO}

O levantamento fitossociológico apontou um total de 176 indivíduos arbóreos em 0,15 ha na Mata do Amador; a Tabela 1 apresenta os parâmetros fitossociológicos calculados. Nove indivíduos $(5,11 \%$ do total) estavam mortos em pé.

Segundo Primack \& Rodrigues (2001), o número elevado de árvores mortas em pé está associado à fragmentação de hábitats e ao consequente efeito de borda. Tais condições favorecem o aumento da radiação solar e dos ventos quentes no interior do fragmento, alterando o microclima da floresta sendo, portanto, a provável causa do elevado número de indivíduos mortos em pé na Mata do Amador. Quanto à relação entre a evolução do estágio sucessional e o número de indivíduos mortos em pé, Swaine (1989) afirma que as diferentes condições ambientais a que uma comunidade é submetida impossibilitam a determinação de tendências no desenvolvimento de florestas tropicais com base apenas no número de indivíduos mortos. Além de características ambientais, tal inferência torna-se inviável devido à falta de parâmetros para determinação da dinâmica de mortalidade, ou seja, ao tempo de morte da árvore e do grupo ecológico a que o indivíduo pertencia.

Dentre as espécies com maior ocorrência destacaram-se Sorocea bonplandii (25), Cupania oblongifolia e Astrocarium aculeatissimum (11) e Mabea fistulifera (8), que juntas somaram 55 indivíduos (ca. 30\%). Os maiores valores de importância (IVI) foram de Sorocea bonplandii (27,21\%), Cupania oblongifolia (19,65\%), Pseudopiptadenia contorta (15,52\%), Astrocaryum aculeatissimum (14,62\%), Swartzia langsdorffii (14,22\%), Apuleia leiocarpa (13,78\%) e Piptadenia gonoacantha $(12,64 \%)$. O índice de valor de importância (IVI) é um indicativo da contribuição das espécies para a estrutura fitossociologica da comunidade, sendo o resultado do 
Tabela 1. Parâmetros fitossociológicos calculados para a comunidade vegetal ocorrente no Parque Municipal da Mata do Amador, Piraí, RJ (NI: número de indivíduos; AB: abundância; FA: frequência absoluta; FR: frequência relativa; DA: densidade absoluta; DR: densidade relativa; DoA: dominância absoluta; DoR: dominância relativa; IVI: índice de valor de importância; H’: índice de Shannon; J’: índice de equabilidade de Pielou).

Table 1. Phitosocilogical parameters calculated for the arboreal community in the Parque Municipal da Mata do Amador, Municipality of Piraí, State of Rio de Janeiro (NI: Number of individuals; AB: Abundance; FA: Absolute frequency; FR: Relative frequency; DA: Absolute density; DR: Density; DoA: Absolute Dominance; DoR: Relative Dominance; IVI: Importance Value Index; H’: Shannon index; J': Pielou Index of equability).

\begin{tabular}{|c|c|c|c|c|c|c|c|c|c|c|c|}
\hline ESPÉCIES & $\mathbf{A B}$ & NI & FA & FR & DA & DR & DoA & DoR & IVI & $\mathbf{H}^{\prime}$ & $\mathbf{J}^{\prime}$ \\
\hline Sorocea bonplandii & 25 & 8 & 53,33 & 6,67 & 166,67 & 14,20 & 1,40 & 6,34 & 27,21 & $-0,28$ & 0,884 \\
\hline Cupania oblongifolia & 11 & 7 & 46,67 & 5,83 & 73,33 & 6,25 & 1,67 & 7,57 & 19,65 & $-0,17$ & \\
\hline Pseudopiptadenia contorta & 5 & 4 & 26,67 & 3,33 & 33,33 & 2,84 & 2,06 & 9,34 & 15,52 & $-0,10$ & \\
\hline Astrocaryum aculeatissimum & 11 & 6 & 40,00 & 5,00 & 73,33 & 6,25 & 0,74 & 3,37 & 14,62 & $-0,17$ & \\
\hline Swartzia langsdorffii & 7 & 3 & 20,00 & 2,50 & 46,67 & 3,98 & 1,71 & 7,74 & 14,22 & $-0,13$ & \\
\hline Apuleia leiocarpa & 2 & 2 & 13,33 & 1,67 & 13,33 & 1,14 & 2,42 & 10,98 & 13,78 & $-0,05$ & \\
\hline Piptadenia gonoacantha & 3 & 3 & 20,00 & 2,50 & 20,00 & 1,70 & 1,86 & 8,43 & 12,64 & $-0,07$ & \\
\hline Mortas & 9 & 5 & 33,33 & 4,17 & 60,00 & 5,11 & 0,51 & 2,30 & 11,58 & $-0,15$ & \\
\hline Nectandra membranacea & 6 & 5 & 33,33 & 4,17 & 40,00 & 3,41 & 0,80 & 3,64 & 11,21 & $-0,12$ & \\
\hline Picramnia ramiflora & 6 & 4 & 26,67 & 3,33 & 40,00 & 3,41 & 0,83 & 3,76 & 10,50 & $-0,12$ & \\
\hline Mabea fistulifera & 8 & 3 & 20,00 & 2,50 & 53,33 & 4,55 & 0,42 & 1,92 & 8,97 & $-0,14$ & \\
\hline Astronium graveolens & 5 & 4 & 26,67 & 3,33 & 33,33 & 2,84 & 0,49 & 2,22 & 8,39 & $-0,10$ & \\
\hline Erythroxylum pulchrum & 6 & 3 & 20,00 & 2,50 & 40,00 & 3,41 & 0,34 & 1,56 & 7,46 & $-0,12$ & \\
\hline Siparuna guianensis & 6 & 4 & 26,67 & 3,33 & 40,00 & 3,41 & 0,15 & 0,66 & 7,41 & $-0,12$ & \\
\hline Eugenia candolleana & 4 & 4 & 26,67 & 3,33 & 26,67 & 2,27 & 0,34 & 1,56 & 7,17 & $-0,09$ & \\
\hline Guateria nigrescens & 4 & 4 & 26,67 & 3,33 & 26,67 & 2,27 & 0,14 & 0,62 & 6,23 & $-0,09$ & \\
\hline Guapira opposita & 3 & 3 & 20,00 & 2,50 & 20,00 & 1,70 & 0,31 & 1,41 & 5,61 & $-0,07$ & \\
\hline Brosimum guianense & 3 & 3 & 20,00 & 2,50 & 20,00 & 1,70 & 0,24 & 1,08 & 5,28 & $-0,07$ & \\
\hline Miconia budlejoides & 4 & 2 & 13,33 & 1,67 & 26,67 & 2,27 & 0,09 & 0,40 & 4,34 & $-0,09$ & \\
\hline Platypodium elegans & 2 & 2 & 13,33 & 1,67 & 13,33 & 1,14 & 0,32 & 1,46 & 4,26 & $-0,05$ & \\
\hline Croton floribundus & 1 & 1 & 6,67 & 0,83 & 6,67 & 0,57 & 0,61 & 2,75 & 4,16 & $-0,03$ & \\
\hline Psychotria vellosiana & 4 & 1 & 6,67 & 0,83 & 26,67 & 2,27 & 0,23 & 1,03 & 4,14 & $-0,09$ & \\
\hline Myrcia fallax & 2 & 2 & 13,33 & 1,67 & 13,33 & 1,14 & 0,21 & 0,96 & 3,77 & $-0,05$ & \\
\hline Tapirira guianensis & 1 & 1 & 6,67 & 0,83 & 6,67 & 0,57 & 0,51 & 2,31 & 3,71 & $-0,03$ & \\
\hline Ficus enormis & 2 & 2 & 13,33 & 1,67 & 13,33 & 1,14 & 0,19 & 0,84 & 3,65 & $-0,05$ & \\
\hline Casearia sylvestris & 2 & 2 & 13,33 & 1,67 & 13,33 & 1,14 & 0,13 & 0,61 & 3,41 & $-0,05$ & \\
\hline Sparattosperma leucanthum & 2 & 2 & 13,33 & 1,67 & 13,33 & 1,14 & 0,13 & 0,59 & 3,40 & $-0,05$ & \\
\hline Himatanthus bracteatus & 2 & 2 & 13,33 & 1,67 & 13,33 & 1,14 & 0,09 & 0,41 & 3,21 & $-0,05$ & \\
\hline Eugenia brasiliensis & 2 & 2 & 13,33 & 1,67 & 13,33 & 1,14 & 0,08 & 0,37 & 3,17 & $-0,05$ & \\
\hline Abarema cochliocarpos & 2 & 2 & 13,33 & 1,67 & 13,33 & 1,14 & 0,07 & 0,31 & 3,12 & $-0,05$ & \\
\hline Senna multijuga & 1 & 1 & 6,67 & 0,83 & 6,67 & 0,57 & 0,34 & 1,54 & 2,94 & $-0,03$ & \\
\hline Cecropia glaziovi & 1 & 1 & 6,67 & 0,83 & 6,67 & 0,57 & 0,26 & 1,18 & 2,58 & $-0,03$ & \\
\hline Cabralea canjerana & 2 & 1 & 6,67 & 0,83 & 13,33 & 1,14 & 0,13 & 0,59 & 2,56 & $-0,05$ & \\
\hline Marlierea sp.1 & 1 & 1 & 6,67 & 0,83 & 6,67 & 0,57 & 0,22 & 1,02 & 2,42 & $-0,03$ & \\
\hline Erythrina speciosa & 1 & 1 & 6,67 & 0,83 & 6,67 & 0,57 & 0,21 & 0,95 & 2,36 & $-0,03$ & \\
\hline Simira sampaioana & 2 & 1 & 6,67 & 0,83 & 13,33 & 1,14 & 0,03 & 0,16 & 2,13 & $-0,05$ & \\
\hline Cupania fluminensis & 1 & 1 & 6,67 & 0,83 & 6,67 & 0,57 & 0,14 & 0,63 & 2,03 & $-0,03$ & \\
\hline Bathysa australis & 1 & 1 & 6,67 & 0,83 & 6,67 & 0,57 & 0,12 & 0,55 & 1,96 & $-0,03$ & \\
\hline Pereskia grandifolia & 1 & 1 & 6,67 & 0,83 & 6,67 & 0,57 & 0,11 & 0,49 & 1,89 & $-0,03$ & \\
\hline Casearia ulmifolia & 1 & 1 & 6,67 & 0,83 & 6,67 & 0,57 & 0,08 & 0,37 & 1,77 & $-0,03$ & \\
\hline Aniba firmula & 1 & 1 & 6,67 & 0,83 & 6,67 & 0,57 & 0,06 & 0,29 & 1,70 & $-0,03$ & \\
\hline Alchornea triplinervia & 1 & 1 & 6,67 & 0,83 & 6,67 & 0,57 & 0,06 & 0,26 & 1,66 & $-0,03$ & \\
\hline Trichilia hirta & 1 & 1 & 6,67 & 0,83 & 6,67 & 0,57 & 0,06 & 0,26 & 1,66 & $-0,03$ & \\
\hline Dalbergia frutescens & 1 & 1 & 6,67 & 0,83 & 6,67 & 0,57 & 0,04 & 0,20 & 1,60 & $-0,03$ & \\
\hline
\end{tabular}


Tabela 1. Continuação...

Table 1. Continued...

\begin{tabular}{lccccccccccc}
\multicolumn{1}{c}{ ESPÉCIES } & AB & NI & FA & FR & DA & DR & DoA & DoR & IVI & H' & J' \\
Chomelia brasiliana & 1 & 1 & 6,67 & 0,83 & 6,67 & 0,57 & 0,04 & 0,18 & 1,58 & $-0,03$ & \\
Rutaceae sp.1 & 1 & 1 & 6,67 & 0,83 & 6,67 & 0,57 & 0,04 & 0,18 & 1,58 & $-0,03$ & \\
Guarea kunthiana & 1 & 1 & 6,67 & 0,83 & 6,67 & 0,57 & 0,04 & 0,16 & 1,56 & $-0,03$ & \\
Syzygium jambos & 1 & 1 & 6,67 & 0,83 & 6,67 & 0,57 & 0,03 & 0,15 & 1,55 & $-0,03$ & \\
Schefflera morototoni & 1 & 1 & 6,67 & 0,83 & 6,67 & 0,57 & 0,03 & 0,14 & 1,54 & $-0,03$ & \\
Bauhinia forficata & 1 & 1 & 6,67 & 0,83 & 6,67 & 0,57 & 0,03 & 0,12 & 1,52 & $-0,03$ & \\
Rustia gracilis & 1 & 1 & 6,67 & 0,83 & 6,67 & 0,57 & 0,02 & 0,11 & 1,51 & $-0,03$ & \\
Lacistema sp.1 & 1 & 1 & 6,67 & 0,83 & 6,67 & 0,57 & 0,00 & 0,00 & 1,40 & $-0,03$ \\
Total & 176 & & 800,00 & 100,00 & 1173,33 & 100,00 & 22,05 & 100,00 & 300,00 & $-3,52$ &
\end{tabular}

somatório da frequência, densidade e dominância da espécie (Felfili et al., 2011). Embora em área restrita, as espécies com maior IVI na Mata do Amador são típicas da Floresta Atlântica e testemunho da vegetação nativa ali remanescente.

Os estudos em florestas estacionais no Sudeste Brasileiro foram desenvolvidos principalmente nos estados de Minas Gerais e São Paulo (Ivanauskas, 1999, 2000; Meira-Neto \& Martins, 2002; Botrel et al., 2000; Coraiola \& Netto, 2003; Silva et al., 2003; Rodrigues et al., 2003; Gonzaga, 2008; Carvalho et al., 2007; Reis et al., 2007; Soares, 2007) e apontam Copaifera lagsdorffi Desf. e Machaerium villosum Vogel como os maiores IVI de florestas estacionais. Tais dados indicam uma composição florística distinta daquela encontrada na Mata do Amador e demais formações florestais do Médio Vale do Paraíba do Sul, uma vez que as espécies citadas sequer ocorrem no estado do Rio de Janeiro (JBRJ, 2014). Outro exemplo é a ocorrência de Sorocea bonplandii, conforme verificado por Soares (2007), Ivanauskas (1999) e Botrel et al. (2000) para o estado de São Paulo, entretanto com IVI muito abaixo daquele encontrado na Mata do Amador. A composição florística diferenciada entre a área estudada e outros inventários pode ser causada pela ocorrência das florestas estacionais estudadas em zonas ecotonais entre Floresta Atlântica e Cerrado.

Dentre os raros trabalhos em floresta estacional no estado do Rio de Janeiro, Dan (2010) registraram as espécies Apuleia leiocarpa e Pseudopiptadenia contorta com IVI elevados no município de São José de Ubá, assim como no presente estudo, reforçando a hipótese de baixa similaridade florística entre as florestas estacionais do Rio de Janeiro e as de Minas Gerais e São Paulo.
Para determinação efetiva de possíveis diferenças estruturais e na composição florística em comunidades florestais da Região Sudeste podem ser empregadas análises de agrupamentos (Torres, 1989; Silva, 1989; Salis, 1990; Siqueira, 1994; Oliveira-Filho et al., 1994), que permitem a visualização da proximidade florística entre as comunidades e o consequente entendimento da fitogeografia regional (Meira-Neto \& Martins, 2002). Porém, devido à carência de estudos no Médio Vale do Paraíba do Sul, ainda não são possíveis tais análises ou outras inferências.

Considerando-se os valores médios estabelecidos por Miranda \& Diógenes (1998) para florestas tropicais, que variam entre 1,5 e 3,5, raramente ultrapassando 4,5, o índice de Shannon para a Mata do Amador foi de $\mathrm{H}^{\prime}=3,517$ nats ind $^{-1}$, indicando uma diversidade elevada. O índice de equabilidade de Pielou (J'=0,884) pode ser considerado elevado, pois quando próximo de um indica alta diversidade na área e que as espécies são teoricamente abundantes entre as unidades amostrais (Magurran, 1988).

A Tabela 2 apresenta o índice de diversidade de Shannon e o índice de equabilidade de Pielou para diferentes estudos realizados em floresta estacional no Sudeste Brasileiro. Apesar da baixa amostragem na Mata do Amador os índices apresentados indicam uma diversidade considerável, principalmente quando comparada aos fragmentos florestais considerados no estudo de Dan (2010) em São José de Ubá, RJ. A suficiência amostral foi atingida a partir da parcela 11, quando ao incremento de $10 \%$ da área amostral, o número de espécies novas não ultrapassou 10\% do total de espécies amostradas. Isso se deu em função do reduzido tamanho do fragmento. 
Tabela 2. Índice de diversidade de Shannon e índice de equabilidade de Pielou para diferentes estudos realizados em Floresta Estacional Semidecidual no Sudeste Brasileiro (UF: unidade federativa; H': índice de Shannon; J': índice de equabilidade de Pielou).

Table 2. Shannon diversity index and evenness index for different studies in deciduous forest in southeastern Brazil. (UF: federative unit; H’: Shannon index; J': Index of equability of Pielou).

\begin{tabular}{lllcc}
\multicolumn{1}{c}{ AUTOR/DATA } & \multicolumn{1}{c}{ LOCALIDADE } & UF & H' & J' \\
Gonzaga (2008) & TIRADENTES & MG & 4,23 & 0,87 \\
Carvalho et al. (2007) & PIEDADE DO RIO GRANDE & MG & 4,42 & 0,85 \\
\hline Silva et al. (2003) & IBITURUNA & MG & 4,2 & 0,89 \\
Botrel et al. (2000) & INGAÍ & MG & 3,73 & 0,76 \\
\hline Soares (2007) & ARARAS & SP & 3,77 & - \\
Ivanauskas (2000) & PIRACICABA & SP & 3.00 & 0,7 \\
Ivanauskas (1999) & ITATINGA & SP & 3,77 & 0,82 \\
Dan (2010) & SÃO JOSÉ DE UBÁ & RJ & 3,87 & 0,86 \\
Dan (2010) & SÃO JOSÉ DE UBÁ & RJ & 3,63 & 0,85 \\
Dan (2010) & SÃO JOSÉ DE UBÁ & RJ & 3,84 & 0,91 \\
Dan (2010) & SÃO JOSÉ DE UBÁ & RJ & 3,83 & 0,92 \\
Dan (2010) & SÃO JOSÉ DE UBÁ & RJ & 2,81 & 0,8 \\
Dan (2010) & SÃO JOSÉ DE UBÁ & RJ & 4,6 & 0,87 \\
Dan (2010) & SÃO JOSÉ DE UBÁ & RJ & 4,35 & 0,88 \\
PRESENTE ESTUDO & PIRAÍ & RJ & 3,57 & 0,884 \\
\hline
\end{tabular}

Os 176 indivíduos amostrados na Mata do Amador foram reunidos em 51 espécies, 46 gêneros e 24 famílias de plantas arbóreas (Tabela 3). Dentre as famílias com maior riqueza de espécies, destacaram-se Fabaceae, com 10 espécies, Myrtaceae e Rubiaceae, com 5, e Moraceae, Meliaceae e Euphorbiaceae, com 3. Outras 4 famílias apresentaram 2 espécies e as 14 restantes foram representadas por apenas 1 cada. A riqueza de Fabaceae, assim como de Myrtaceae e Rubiaceae é típica dos ecossistemas Florestais da Floresta Atlântica no estado do Rio de Janeiro (Marques, 1997; Conde et al., 2005; Carvalho et al., 2007; Guedes-Bruni \& Lima, 1994; Dan, 2010). A elevada riqueza de Fabaceae pode ser atribuída a associações simbióticas com bactérias fixadoras de nitrogênio atmosférico, estratégia evolutiva que, além de favorecer a fertilidade do solo, possibilita o desenvolvimento de seus indivíduos inclusive em condições ambientais adversas (Kerbauy, 2004). Já Myrtaceae e Rubiaceae são a $5^{\mathrm{a}}$ e $6^{\mathrm{a}}$ maiores famílias em número de espécies no bioma, sendo a $2^{\mathrm{a}}$ e $3^{\mathrm{a}}$ mais abundante em Florestas Estacionais, respectivamente (Stehmann et al., 2009).

Quanto à riqueza de gêneros, Fabaceae novamente foi a mais diversa (10), seguida por Rubiaceae (5), Myrtaceae (4), Moraceae, Meliaceae e Euphorbiaceae (3 cada) e Lauraceae, Anacardiaceae, Salicaceae e Sapindaceae (2 cada). Os gêneros mais representativos quanto ao número de indivíduos foram Cupania L., Casearia Jacq e Eugenia L., com duas espécies cada, sendo os demais 41 gêneros representados por apenas uma espécie. As espécies levantadas são nativas, com exceção de Syzygium jambos (jambo).

Com relação ao grupo ecológico das espécies e o estado de conservação da Mata do Amador, a maioria das espécies estudadas são pioneiras. Entretanto foram registradas as espécies clímax Guateria nigrescens, Apuleia leiocarpa e Aniba firmula e ainda 10 espécies (20,5\%) classificadas como secundárias (Tabela 3), todas típicas da floresta atlântica. Espécies clímax se desenvolvem em condições de insolação indireta, umidade elevada e solos eutróficos (Lorenzi, 2002). Contudo, prevalecem espécies pioneiras na área de estudo, a ocorrência de espécies clímax e secundárias típicas da floresta atlântica é um bom indicativo da resiliência dessa comunidade. Não foram obtidos dados na bibliografia sobre 11 espécies amostradas (20,5\%) (Tabela 3).

Do total de espécies levantadas na Mata do Amador, 35 (68\%) foram classificadas como zoocóricas; 11 espécies (21\%), como autocóricas; e 5 (11\%) dispersam seus frutos ou sementes pelo vento (anemocóricas) (Tabela 3). O conhecimento a respeito da dispersão das sementes permite inferir o grau de regeneração das comunidades vegetais, sendo um indicativo da 
Tabela 3. Espécies arbóreas do Parque Municipal da Mata do Amador, Piraí, RJ, incluindo seu grupo ecológico e forma de dispersão. si: sem informação.

Table 3. Arboreal species of the Parque Municipal da Mata do Amador, Piraí-RJ, including their ecological group and form of dispersion. si: No information.

\begin{tabular}{|c|c|c|c|}
\hline FAMÍLIA & ESPÉCIES & $\begin{array}{c}\text { GRUPO } \\
\text { ECOLÓGICO }\end{array}$ & DISPERSÃO \\
\hline \multirow[t]{2}{*}{ ANACARDIACEAE } & Astronium graveolens Jacq. & secundária & autocórica \\
\hline & Tapirira guianensis Aubl. & pioneira & zoocórica \\
\hline ANNONACEAE & Guateria nigrescens Mart. & clímax & zoocórica \\
\hline APOCYNACEAE & Himatanthus bracteatus (A. DC.) Woodson. & secundária & autocórica \\
\hline ARALIACEAE & Schefflera morototoni (Aubl.) Decne. e Planch. & si & zoocórica \\
\hline ARECACEAE & Astrocaryum aculeatissimum (Schott) Burret & secundária & anemocórica \\
\hline BIGNONIACEAE & Sparattosperma leucanthum (Vell.) K. Schum. & secundária & anemocórica \\
\hline CACTACEAE & Pereskia grandifolia Haw. & secundária & autocórica \\
\hline CECROPIACEAE & Cecropia glaziovi Snethl. & pioneira & zoocórica \\
\hline ERYTHROXYLACEAE & Erythroxylum pulchrum A. St.-Hil. & secundária & zoocórica \\
\hline \multirow{3}{*}{ EUPHORBIACEAE } & Alchornea triplinervia (Spreng.) Müll. Arg. & pioneira & zoocórica \\
\hline & Croton floribundus Spreng. & pioneira & zoocórica \\
\hline & Mabea fistulifera Mart. & pioneira & zoocórica \\
\hline \multirow[t]{10}{*}{ FABACEAE } & Abarema cochliocarpos Gomes Barneby e Grimes & si & zoocórica \\
\hline & Apuleia leiocarpa (Vogel) J. F. Macbr. & secundária & autocórica \\
\hline & Bauhinia forficata Link & secundária & zoocórica \\
\hline & Dalbergia frutescens (Vell.) Britton & pioneira & zoocórica \\
\hline & Erythrina speciosa Andrews & pioneira & autocórica \\
\hline & Piptadenia gonoacantha (Mart.) J. F. Macbr. & pioneira & zoocórica \\
\hline & Platypodium elegans Vogel & pioneira & zoocórica \\
\hline & Pseudopiptadenia contorta (DC.) G. P. Lewis e M. P. Lima & secundária & zoocórica \\
\hline & Senna multijuga (Rich.) Irwin e Barn. & secundária & zoocórica \\
\hline & Swartzia langsdorffii Raddi & pioneira & autocórica \\
\hline LACISTEMATACEAE & Lacistema sp. & (vazio) & zoocórica \\
\hline \multirow[t]{2}{*}{ LAURACEAE } & Aniba firmula (Nees e Mart.) Mez & clímax & zoocórica \\
\hline & Nectandra membranacea (Sw.) Griseb. & pioneira & zoocórica \\
\hline MELASTOMATACEAE & Miconia budlejoides Triana & si & anemocórica \\
\hline \multirow[t]{3}{*}{ MELIACEAE } & Cabralea canjerana (Vell.) Mart & si & si \\
\hline & Guarea kunthiana A. Juss. & clímax & zoocórica \\
\hline & Trichilia hirta L. & pioneira & zoocórica \\
\hline \multirow[t]{3}{*}{ MORACEAE } & Brosimum guianense (Aubl.) Huber & si & si \\
\hline & Ficus enormis (Mart. ex Miq.) Miq & secundária & si \\
\hline & Sorocea bonplandii (Baill.) W. C. Burger, Lanj. e Wess. Boer & pioneira & zoocórica \\
\hline \multirow[t]{5}{*}{ MYRTACEAE } & Eugenia brasiliensis Lam & pioneira & zoocórica \\
\hline & Eugenia candolleana D. C. & si & si \\
\hline & Marlierea sp.1 & si & si \\
\hline & Myrcia fallax (Rich.) DC. & si & si \\
\hline & Syzygium jambos (L.) Alston. Turrialba & pioneira & autocórica \\
\hline NYCTAGINACEAE & Guapira opposita (Vell.) Reitz & pioneira & anemocórica \\
\hline PICRAMNIACEAE & Picramnia ramiflora Planch. & pioneira & anemocórica \\
\hline \multirow[t]{5}{*}{ RUBIACEAE } & Bathysa australis (A. St.-Hil.) K. Schum. & si & si \\
\hline & Chomelia brasiliana A. Rich & si & si \\
\hline & Psychotria vellosiana Benth. & si & si \\
\hline & Rustia gracilis K. Schum. & secundária & zoocórica \\
\hline & Simira sampaioana (Standl.) Steyerm. & pioneira & autocórica \\
\hline RUTACEAE & Rutaceae sp.1 & pioneira & anemocórica \\
\hline \multirow[t]{2}{*}{ SALICACEAE } & Casearia sylvestris Sw. & pioneira & zoocórica \\
\hline & Casearia ulmifolia Vahl ex Vent & secundária & zoocórica \\
\hline \multirow[t]{2}{*}{ SAPINDACEAE } & Cupania fluminensis Acev.-Rodr. Radlk. & pioneira & anemocórica \\
\hline & Cupania oblongifolia Mart. & secundária & zoocórica \\
\hline SIPARUNACEAE & Siparuna guianensis Aubl. & pioneira & zoocórica \\
\hline
\end{tabular}


presença de populações animais, do potencial de oferta de propágulos e fornece parâmetro para escolha das espécies a serem empregadas em reflorestamentos. A elevada proporção de espécies zoocóricas encontrada na Mata do Amador corrobora os padrões descritos para florestas tropicais (Morellato \& Leitão-Filho, 1992; Penhalber \& Mantovani, 1997; Rossi, 1994). Ademais, indica ainda que essa vegetação fornece subsídios para a fauna associada típica da floresta atlântica.

A Mata do Amador é classificada como um fragmento secundário de Floresta Estacional Semidecidual em estágio médio de regeneração, já que preenche os seguintes quesitos: diâmetro médio de $12,75 \mathrm{~cm}$, área basal média $3,307 \mathrm{~m}^{2}$, ou o equivalente a 22,04 $\mathrm{m}^{2} \mathrm{ha}^{-1}$, e altura média de $8,04 \mathrm{~m}$. Quanto à existência, diversidade e quantidade de epífitas, essas estão presentes principalmente nas cotas mais baixas, próximas às margens do Rio Piraí, sendo representadas por espécies de Bromeliaceae e Orchidaceae. O dossel apresenta-se predominantemente contínuo, com copas superiores horizontalmente amplas, cobrindo o solo sob o fragmento. A serrapilheira é sempre presente e o sub-bosque apresenta notadamente três estratos definidos. Trepadeiras ocorrem principalmente nas bordas do fragmento e lianas, exclusivamente no interior da comunidade. Além da ocorrência de espécies como Guarea guidonia (carrapeta), Tabebuia chrysotricha (ipê-amarelo), Cybistax antisyphilitica (ipê-verde), indicadoras de formações secundárias em estágio médio de regeneração no estado do Rio de Janeiro (Brasil, 2008).

Tendo em vista o tamanho reduzido desse fragmento e a distância de fontes de propágulo, a riqueza de espécies na Mata do Amador é baixa quando comparada a outras áreas estudadas. Por outro lado, além da representação dos grupos típicos da floresta atlântica estacional, a diversidade de táxons nas diferentes categorias taxonômicas é um bom indicativo da biodiversidade local.

\section{CONCLUSÕES}

O fragmento de floresta secundária ocorrente na Mata do Amador encontra-se atualmente em estágio médio de regeneração. Sua condição atual é atribuída à elevada resiliência do ecossistema, favorecida pela restrição do acesso e pela conscientização da população. Desta forma, o emprego de medidas restritivas e a subsequente interligação dos fragmentos apresentam-se com uma forma simples e eficiente de recuperação de comunidades vegetais no Médio Vale do Paraíba do Sul.

A diversidade de espécies ( $\left.\mathrm{H}^{\prime}\right)$ apresentou valores relativamente altos. Tais valores indicam que em regiões onde predominam hábitats fragmentados com dimensões inferiores a 1 ha é possível e imprescindível a realização de estudos fitossociológicos. Essas comunidades resguardam material genético, atuam como fonte de propágulo, área de refúgio e desenvolvimento de espécies da fauna, realizam suas funções hidrológicas e de conservação dos solos e representam o verdadeiro quadro em que se encontram as Florestas Estacionais no Médio Vale do Paraíba do Sul.

A análise do índice de valor de importância (IVI) de espécies da floresta estacional fluminense e de outras regiões do Sudeste aponta uma possível diferença estrutural e florística entre as localidades. Faz-se necessário, portanto, a ampliação de estudos estruturais na floresta estacional do Rio de Janeiro, de modo a permitir a realização de análises que determinem o grau de similaridade entre as comunidades, entre outros aspectos.

\section{AGRADECIMENTOS}

\section{Ao PPGCAF}

\section{STATUS DA SUBMISSÃO}

Recebido: 25 jul., 2014

Aceito: 10 jan., 2016

\section{AUTOR(ES) PARA CORRESPONDÊNCIA}

\section{Marcos Gervasio Pereira}

Departamento de Solos, Universidade Federal Rural do Rio de Janeiro - UFRRJ, BR 465, Km 7, CEP 23897-900, Seropédica, RJ, Brasil e-mail: gervasio@ufrrj.br

\section{REFERÊNCIAS}

Ab'Sáber AN. O domínio dos mares-de-morros no Brasil. São Paulo: IGEOG-USP; 1966. Geomorfologia, 2.

Bergalho HG. Estratégias e ações para a conservação da biodiversidade no Estado do Rio de Janeiro. Rio de Janeiro: Instituto Biomas; 2009. 344 p. 
Botrel RT, Oliveira-Filho AT, Rodrigues LA, Curi N. Influência do solo e topografia sobre as variações da composição florística e estrutura da comunidade arbóreo-arbustiva de uma floresta estacional semidecidual em Ingaí, MG. Brazilian Journal of Botany 2000; 25(2): 195-213. http:// dx.doi.org/10.1590/S0100-84042002000200008.

Brasil. Conselho Nacional do Meio Ambiente. Resoluções do Conama: resoluções vigentes publicadas entre julho de 1984 e novembro de 2008, $n^{\circ} 10$ e $n^{\circ} 6.2$. ed. Brasília: Conama; 2008. 927 p.

Câmara IG. Plano de ação da Mata Atlântica. São Paulo: Fundação S.O.S. Mata Atlântica; 1991.

Caraiola M, Netto SP. Análise da estrutura horizontal de uma floresta estacional semidecidual localizada no município de Cássia-MG. Revista Acadêmica: Ciências Agrárias e ambientais 2003; 1(2): 11-19.

Carvalho FA, Nascimento MT, Braga JMA. Estrutura e composição florística do estrato arbóreo de um remanescente de Mata Atlântica submontana no município de Rio Bonito, RJ, Brasil (Mata Rio Vermelho). Revista Árvore 2007; 31(4): 717-730.

Carvalho PER. Espécies arbóreas brasileiras. Brasília: Embrapa Informação Tecnológica; 2003.

Conde MSC, Lima HRP, Peixoto AL. Aspectos florísticos e vegetacionais da Marambaia, Rio de Janeiro, Brasil. In: Menezes LFT, Peixoto AL, Araújo DSD, editores. História natural da Marambaia. Seropédica: EDUR; 2005. p. 133-168.

Dan ML. Estrutura da comunidade arbórea de fragmentos de floresta estacional estacional semidecidual na bacia hidrográfica do rio São Domingos, Rio de Janeiro, Brasil. Rodriguésia 2010; 61(4): 749-766.

Dean W. A Ferro e fogo, a história e a devastação da Mata Atlântica brasileira. São Paulo: Companhia das Letras; 1996.

Felfili JM, Eisenlohr PV, Melo MMRF, Andrade LA, Meira-Neto JAA. Fitossociologia no Brasil: métodos e estudos de casos. Viçosa: Editora UFV; 2011.

Gonzaga APD. Diagnóstico florístico-estrutural do componente arbóreo da floresta da Serra de São José, Tiradentes, MG, Brasil. Acta Botanica Brasilica 2008; 22(2): 505-520.

Guedes-Bruni RR, Lima MPM. Abordagem geográfica, fitofisionômica, florística e taxonômica da Reserva Ecológica de Macaé de Cima. In: Lima MPM, Guedes-Bruni RR, organizadores. Reserva ecológica de Macaé de Cima, RJ: aspectos florísticos das espécies vasculares. Rio de Janeiro: Jardim Botânico do Rio de Janeiro; 1994.

Instituto Brasileiro de Geografia e Estatística - IBGE. Manual técnico da Vegetação Brasileira: Sistema fitogeográfico, Inventário das formações florestais e campestres, Técnicas e manejo de coleções botânicas e procedimentos para mapeamentos. 2. ed. Rio de Janeiro: IBGE; 2012.
Ivanauskas NM. Fitossociologia de um trecho de Floresta Estacional Semidecidual em Itatinga, São Paulo, Brasil. Scientia Forestalis 1999; 56: 83-99.

Ivanauskas NM. Florística e Fitossociologia de remanescentes de floresta estacional decidual em Piracicaba, São Paulo, Brasil. Revta brasil. Bot. 2000; 23(3): 291-304.

Jardim Botânico do Rio de Janeiro - JBRJ. Lista de Espécies da Flora do Brasil [online]. Rio de Janeiro: Jardim Botânico do Rio de Janeiro; 2014 [cited 2014 abr 1]. Disponível em: http://floradobrasil.jbrj.gov.br

Kerbauy GB. Fisiologia vegetal. São Paulo: Guanabara Koogan; 2004. p. 76-93.

Köppen W. Climatologia: com um estúdio de los climas de La tierra. Ciudad de México: Fondo de Cultura Económica; 1948.

Lima MPM, Guedes-Bruni RR. Reserva ecológica de Macaé de Cima: Nova Friburgo - RJ: aspectos florísticos das espécies vasculares. Rio de Janeiro: Jardim Botânico do Rio de Janeiro; 1996. vol. 2.

Lorenzi H. Árvores Brasileiras, manual de identificação e cultivo de plantas arbóreas do Brasil. 4. ed. Nova Odessa: Instituto Plantarum; 2002.

Lorenzi H. Árvores Brasileiras, manual de identificação e cultivo de plantas arbóreas do Brasil. 2. ed. Nova Odessa: Istituto Plantarum; 2009.

Magurran AE. Ecological diversity and its measurement. New Jersey: Princenton University Press; 1988

Marques CM. Mapeamento da cobertura vegetal e listagem de espécies ocorrentes na Área de Proteção Cairuçu, Município de Paraty, RJ. Rio de Janeiro: Jardim Botânico do Rio de Janeiro; 1997.

Meira-Neto JAA, Martins FR. Composição florística de uma floresta estacional semidecidual Montana no município de Viçosa-MG. Revista Árvore 2002; 26(4): 437-446.

Menezes LFT, Araújo DSD. Formações vegetais da restinga da Marambaia, Rio de Janeiro. In: Menezes LFT, Peixoto AL, Araújo DSD, editores. História natural da Marambaia. Seropédica: Edur; 2005.

Miranda IS, Diógenes MB. Caracterização florística, fisionômica e estrutural da vegetação da floresta nacional do Macauã. Rio Branco; 1998. Relatório técnico.

Morellato LPC, Leitão-Filho HF. Padrões de frutificação e dispersão na Serra do Japi. In: Morellato LPC, organizadores. História natural da Serra do Japi: ecologia e preservação de uma área florestal no Sudeste do Brasil. Campinas: Editora da UNICAMP; 1992. p. 112-140.

Morim MP. Leguminosas Arbustivas e Arbóreas da Floresta Atlântica do Parque Nacional do Itatiaia, Sudeste do Brasil: Padrões de Distribuição. Rodriguesia 2006; 57(1): 27-45.

Oliveira JA. Caracterização da bacia do Ribeirão Cachimbal - Pinheiral, RJ e de suas principais paisagens degradadas 
[dissertação]. Seropédica: Instituto de Florestas, Universidade Federal Rural do Rio de Janeiro; 1998.

Oliveira RR, Zaú AS, Lima DF, Silva MBR, Vianna MC, Sodré DO et al. Significado ecológico da orientação de encostas no Maciço da Tijuca, Rio de Janeiro. Oecologia Brasiliensis; Volume I: Estrutura, Funcionamento e Manejo de Ecossistemas Brasileiros 1995; 524-541.

Oliveira-Filho AT, Fontes AL. Patterns of Floristic Differentiation among Atlântic Forest in Southeastern Brazil and the Influence of Climate. Biotropica 2000; 32(4b): 793-810. http://dx.doi.org/10.1111/j.1744-7429.2000. tb00619.x.

Oliveira-Filho AT, Scolforo JRS, Mello JM. Composição florística e estrutura comunitária de um remanescente de floresta semidecidua Montana em Lavras, MG. Revista Brasileira de Botânica 1994; 17(2): 169-184.

Penhalber EF, Mantovani W. Floração e chuva de sementes em mata secundária em São Paulo, SP. Revista brasileira de Botânica 1997; 20(2): 205-220.

Primack RB, Rodrigues E. Biologia da Conservação. 10. ed. Londrina: Editora Planta; 2001.

Reis H, Scolforo JRS, Oliveira AD, Oliveira-Filho AT, Mello JM. Análise da composição florística, diversidade e similaridade de fragmentos de mata atlântica em Minas Gerais. Cerne 2007; 13(3): 280-290.

Rodrigues LA, Carvalho DA, Oliveira-Filho AT, Botrel RT, Silva EA. Florística e estrutura da comunidade arbórea de um fragmento florestal em Luminárias, MG. Acta bot. Brás 2003; 17(1): 71-87.

Rossi L. A flora arbórea-arbustiva da mata da reserva da Cidade Universitária "Armando de Salles Oliveira" (São Paulo, Brasil). São Paulo: Instituto de Botânica; 1994. Boletim do Instituto de Botânica n. 9.

Salis SM. Composição florística e estrutura de um remanescente de mata ciliar do Rio Jacaré-Pepira, Brotas, SP [dissertação]. Campinas: Universidade de Campinas; 1990.

Santos RD, Lemos RC, Santos HG, Ker JC, Anjos LGH. Manual de descrição e coleta de solo no campo. Viçosa: Sociedade Brasileira de Ciência do Solo; 2005.

Schilling AC, Batista JLF. Curva de Acumulação de espécies e suficiência amostral em florestas tropicais. Revista Brasil Bot 2008; 31(1): 179-187.
Silva AF. Composição florística e estrutura fitossociológica do estrato arbóreo da reserva florestal professor Augusto Ruschi, São José dos Campos, SP [tese]. Campinas: Universidade de Campinas; 1989.

Silva CR. Geodiversidade do Brasil: conhecer o passado, para entender o presente e prever o futuro. Rio de Janeiro: Cássio Roberto da Silva; 2008.

Silva VF, Venturin N, Oliveira-Filho AT, Macedo RLG, Carvalho WAC, Berg EVD. Caracterização estrutural de um fragmento de floresta semidecídua no município de Ibituruna, MG. Cerne 2003; 9(1): 92-106.

Siqueira MF. Análise florística e ordenação de espécies arbóreas da mata atlântica através de dados binários [dissertação]. Campinas: Universidade de Campinas; 1994.

Soares MS. Composição florística e estrutura fitossociológica de uma floresta estacional semidecidual em Araras, SP [dissertação]. São Carlos: Universidade Federal de São Carlos; 2007.

Souza VC, Lorenzi H. Botânica Sistemática - Guia ilustrado para a identificação das famílias de Fanerógamas nativas e exóticas no Brasil, baseado em APG III. Nova Odessa: Plantarum; 2012.

Stehmann JR, Forzza RC, Salino A, Sobral M, Costa DP, Kamino LHY. Plantas da Floresta Atlântica. Rio de Janeiro: Instituto de Pesquisas Jardim Botânico do Rio de Janeiro; 2009

Swaine MD. Population dynamics of tree species in tropical forests. In: Holm-Nielsen LB, Nielsen IC, Balslev $\mathrm{H}$, editors. Tropical forests: botanical dynamics, speciation and diversity. London: Academic Press; 1989.

Torres RB. Estudo florística em mata secundária da Estação Ecológica de Angatuba-SP [dissertação]. Campinas: Universidade de Campinas; 1989.

Vilela EA, Oliveira-Filho AT, Carvalho DA, Gavilanes LM. Fitossociologia e fisionomia da mata semidecidua margeando o reservatório de Camargos em Itutiga, Minas Gerais. Ciência \& Prática 1994; 18(4): 415-424.

Vuono YS. Inventário florístico. In: Sylvestre LS, Rosa MMT, organizadores. Manual metodológico para estudos botânicos na mata atlântica. Seropédica: Edur; 2002. 